\section{TAKING ACCOUNTABILITY}

Sir, Paul Hood was a dental classmate of mine in Queen's University and I was very saddened to hear of his death (Dentist suicides; BDJ 2013; 215: 593-594).

There were 26 people in our year at Queen's University Dental School. Paul was one who committed suicide in December and two months ago another colleague, also our year, committed suicide. Both have pointed to pressures from the dental boards and, in N. Ireland, pressures from the RQIA and Dental Probity. This, I think you would agree, is quite a high proportion, two out of 26.

Over the last ten years in N. Ireland there have been a number of dental suicides. As yet, I am not aware of any 'minister of state for health opening any enquiry into the dental board, BSO or probity department here in N. Ireland' and starting to make them take accountability for their actions.

Perhaps the BDA could take action on this here in Northern Ireland.

M. Haran

By email

DOI: 10.1038/sj.bdj.2014.108
[...] There seems no doubt that this condition exists, yet, because it has no name, it has no official existence.'

So said the great medical philosopher Richard Asher when introducing his newly christened symptom, Texidor's Twinge, to the Medical Society of London in $1959 .^{1}$

2014 marks the anniversary of a new epidemic in the UK of middle aged adults with untreated part-erupted mesioangular impacted lower third molars associated with unrestorable distal cervical caries in the adjacent second molar. ${ }^{2-5}$ We all recognise this symptom complex but so far it lacks a name and hence it has limited clinical acceptance. It is high time we put this right, and I propose it is named the Shepherd Brickley Syndrome in tribute to the two protagonists of non-prophylactic wisdom tooth management who introduced this epidemic to British dentistry 20 years ago. ${ }^{6}$

J. Townend Chichester

1. Asher R. Making sense. In Talking sense. London: Pitman Medical, 1972.

2. McArdle L W, Renton T F. Distal cervical caries in the mandibular second molar: an indication for the prophylactic removal of the third molar? $\mathrm{Br} J$ Oral Maxillofac Surg 2006; 44: 42-45.

3. Allen R T, Witherow H, Collyer J, Roper-Hall $R_{\text {, }}$ Nazir M A, Mathew G. The mesioangular third molar - to extract or not to extract? Analysis of 726 consecutive third molars. Br Dent J 2009; 206: 586-587.

4. Saund D, Dietrich T. The effects of NICE guidelines on the management of third molar teeth. Br Dent J 2012; 213: 230-231.

5. Mansoor J, Jowett A, Coulthard P. NICE or not so NICE? Br Dent J 2013; 215: 209-212.

6. Shepherd J P, Brickley M. Surgical removal of third molars. Br Med J 1994; 309: 620-621.

DOI: 10.1038/sj.bdj.2014.106

\section{EBD}

\section{Squirting sockets}

Sir, I was a little disturbed to see the suggestion that "there is some evidence that rinsing with chlorhexidine or placing chlorhexidine gel in the sockets of extracted teeth provides a benefit in preventing dry socket' in the Evidence Based Dentistry 'toolbox.' ${ }^{1}$ I have some misgivings about this advice.

If chlorhexidine gel is placed in all extraction sockets, what is the likelihood of seeing serious adverse side effects such as anaphylaxis, especially since the use of chlorhexidine (and consequent sensitisation) has become so widespread?

Is this a licensed and safe use of chlorhexidine gel?

Is it wise to use gel from a toothpaste tube parenterally?

If a serious adverse reaction occurred, would our treatment be defensible in court?

I note that some of the papers ${ }^{2}$ reviewed by the Cochrane team mention using gelatine sponges. I haven't used these since the 1970s as I have doubts about sterility and the advisability of using bovine-based materials in some religious and other groups, to say nothing of BSE.

I would draw readers' attention to the last line of the Cochrane Review, ${ }^{3}$ not included in the toolbox, namely that 'it is recommended that all members of the dental team prescribing chlorhexidine products are aware of the potential for both minor and serious adverse side effects'.

All things considered it's probably not a good idea to squirt chlorhexidine gel into fresh tooth sockets.

\section{Howarth London}

1. Richards D. Questions and answers in Evidencebased Dentistry: volume 13. Evid Based Dent 2012 13: 123-127.

2. Haraji A, Rakhshan V, Khamverdi N, Alishahi H K. Effects of intra-alveolar placement of $0.2 \%$ chlorhexidine bioadhesive gel on dry socket incidence and postsurgical pain: a double-blind split-mouth randomized controlled clinical trial. J Orofac Pain 2013; 27: 256-262.

3. Daly B, Sharif M O, Newton T, Jones K, Worthington $H V$. Local interventions for the management of alveolar osteitis (dry socket). Cochrane Database Syst Rev 2012; CD006968. doi: 10.1002/14651858.

DOI: 10.1038/sj.bdj.2014.107 